\title{
Dairy heifers benefit from the presence of an experienced companion when learning how to graze
}

\author{
J. H. C. Costa, ${ }^{*}$ W. G. Costa, † D. M. Weary, ${ }^{*}$ L. C. P. Machado Filho, $†$ and M. A. G. von Keyserlingk*1 \\ *Animal Welfare Program, Faculty of Land and Food Systems, University of British Columbia, Canada, V6T $1 Z 4$ \\ †LETA-Laboratório de Etologia Aplicada e Bem-Estar Animal, Departamento de Zootecnia e Desenvolvimento Rural, \\ Universidade Federal de Santa Catarina, Rod. Admar Gonzaga, 1346-Itacorubi, 88034-001, Florianópolis, SC, Brazil
}

\section{ABSTRACT}

Pasture remains important on many dairy farms, but the age of first contact with pasture varies depending on the month of birth, weaning age, and farm management. Regardless of age, naïve dairy heifers must learn to graze when first introduced to pasture. This study investigated whether being grouped with experienced dairy cows would affect the development of grazing behaviors. Sixty-three Holstein heifers (mean \pm SD 14.2 $\pm 1.3 \mathrm{mo} ; 546 \pm 60.7 \mathrm{~kg})$ and 21 dry Holstein cows $(2.6$ \pm 0.8 lactations; $751 \pm 53.9 \mathrm{~kg}$ ) were assigned into 7 groups of 12 animals (3 dry cows and 9 naïve heifers), and each was divided and assigned to an experienced ( 3 cows and 3 heifers) and nonexperienced (6 heifers) sub-group. Sub-groups were introduced to pasture in different paddocks without visual contact with any other cattle. No difference was found in the time after introduction to the paddock for heifers to first attempt to nibble grass [experienced: 0:23 (0:17-0:43) vs. nonexperienced 0:40 (0:35-0:46); median (quartile 1 - quartile 3), h:mm]. However, heifers grouped with experienced cows showed a shorter latency to begin grazing [experienced: 0:47 (0:28-00:52) vs. nonexperienced 2:13 $(1: 25-2: 30)]$. During the first hour after introduction to pasture, heifers in the experienced treatment showed fewer stomping events [experienced: $2.5(1.25-4)$ vs. nonexperienced: $6.5(4-8)]$ and vocalized less often [experienced: $3.5 \quad(1.25-5.75)$ vs. nonexperienced: 7 (5-8.75)]. After this initial period, animals in both subgroups began to graze normally; treatments did not differ in grazing behaviors over the 3 -d observation period. These results indicate that grouping heifers with pasture-experienced cows improves grazing behavior of dairy heifers in the first hours following introduction to pasture.

Key words: feeding behavior, social learning, social facilitation, dairy replacement, neophobia

Received January 27, 2015.

Accepted September 9, 2015

${ }^{1}$ Corresponding author: nina@mail.ubc.ca

\section{INTRODUCTION}

In the North American dairy industry, indoor housing systems with zero grazing have become increasingly prevalent (Fulwider et al., 2008), with less than 5\% of lactating dairy cattle having access to pasture at some point during the year (NAHMS, 2010). If pasture is used by producers, it is frequently incorporated during the spring and summer months for growing heifers because pasture use results in reduced costs associated with purchased feed and reduction in labor (Hanson et al., 2013).

Beef calves are often born outside and spend much of their early life grazing with their mother and other social partners (Enríquez et al., 2011); in contrast, on intensive dairy farms calves are typically separated from the dam soon after birth (USDA, 2008; Vasseur et al., 2010), reared indoors, and provided no access to pasture until at the earliest after weaning, and sometimes much later depending on season and management on that farm. Lopes et al. (2013) found that providing grazing experience during the growing phase increased grazing time and positively affected milk production when dairy cows introduced to pasture after calving. However, most dairy replacement animals do not have the opportunity to graze when they are young, and often first-season grazing dairy heifers are placed on pasture without any companions.

These first-time grazers are thus faced with several challenges, including learning how to eat a novel feed type (Hessle, 2009; Costa et al., 2014), habituating to a novel environment (De Paula Vieira et al., 2012), and often coping with new conspecifics (De Paula Vieira et al., 2010) as heifers are frequently commingled when put out onto pasture. Numerous challenges are associated with regrouping, particularly in terms of feeding and social behavior (Hasegawa et al., 1997; see also review by von Keyserlingk and Weary, 2010). Thus, the combined effects of regrouping and the introduction to a novel environment may be disruptive to young heifers when transitioning from indoor housing to pasture.

To our knowledge, limited research has been conducted on the challenges that naïve dairy replacement 
heifers face during the introduction to pasture, and acute effects have not been investigated. One possible solution to the challenges faced by first-time grazers is to provide experienced animals that can act as social models. Thus, the aim of this study was to test if the presence of cows with previous experience on pasture would facilitate the development of grazing behavior of naïve dairy heifers when first introduced to pasture.

\section{MATERIALS AND METHODS}

This experiment was conducted between April 25 and July 4, 2013, at The University of British Columbia's (UBC) Dairy Education and Research Centre, located in Agassiz, British Columbia, Canada $\left(49^{\circ} \mathrm{N}, 121^{\circ} \mathrm{W}\right)$. All procedures were approved by the UBC Animal Ethics Committee.

\section{Animals}

A total of 63 pregnant Holstein heifers (mean \pm SD: $14.2 \pm 1.3 \mathrm{mo} ; 546 \pm 60.7 \mathrm{~kg}$; BCS $3.2 \pm 0.5$, range from 2.5 to 4; scored from 1 to 5 following Edmonson et al., 1989) with no previous experience on pasture and 21 nonlactating Holstein cows (2.6 \pm 0.8 lactations; 751 $\pm 53.9 \mathrm{~kg}$; BCS $3.5 \pm 0.5$, range from 2.5 to 4 ) were assigned to 7 groups of 12 animals; each group had 3 nonlactating cows and 9 naïve heifers.

Each group was formed $3 \mathrm{wk}$ before introduction to pasture. All cows had some experience on pasture as growing heifers and in the case of the multiparous cows during the previous summers if they were nonlactating. All experimental animals regardless of age were housed for at least 6 mo before the beginning of the experiment in a freestall barn with no access to the outdoors or to pasture during this time.

\section{Experimental Design}

The experimental period lasted $28 \mathrm{~d}$ per group, and groups were tested consecutively. During the first 21 $\mathrm{d}$, each group was housed indoors in a pen configured with 12 freestalls. On d 22 groups were sub-divided into 2 groups of 6 animals each: 1 with 6 naïve heifers and 1 with 3 naïve heifers and 3 experienced cows. Each sub-group was placed on pasture for $72 \mathrm{~h}$, starting at $0900 \mathrm{~h}$. Treatment order was randomized: one subgroup was placed on pasture first on $\mathrm{d} 22$, and the other sub-group stayed in the home pen until d 25 when they were granted access to pasture.

\section{Housing and Management}

Three experimental pens in a naturally ventilated freestall barn $($ width $=38 \mathrm{~m}$, length $=156 \mathrm{~m})$ with a north-south orientation and curtained sidewalls were used for this experiment. Each pen (width $=9.5 \mathrm{~m}$ and length $=12.3 \mathrm{~m}$ ) had 12 freestalls $(1.2 \mathrm{~m}$ center to center) separated by freestall divider loops with a diameter of $0.89 \mathrm{~m}$ (Y2K stall dividers, Artex, Langley, British Columbia, Canada). The bed of each stall was $2.6 \mathrm{~m}$ long and had a brisket board that was $1.7 \mathrm{~m}$ from the internal side of the curb ( $0.2 \mathrm{~m}$ height), providing a lying area of approximately $2 \mathrm{~m}^{2} / \mathrm{cow}$. The neck rail was positioned $1.2 \mathrm{~m}$ above the stall surface and $1.2 \mathrm{~m}$ from the rear curb of the stall. The stall was covered with a geotextile mattress and bedded with approximately 5 $\mathrm{cm}$ of river sand. Alleys were scraped 8 times per day with an automatic scraper, and crossovers were scraped by hand once per day.

The distance between the pasture and the barn varied according to the paddock used; the closest was $7 \mathrm{~m}$ and the farthest was $65 \mathrm{~m}$ from the barn. The pasture and the barn were connected via a 4.0 -m-wide path covered with bark mulch. The path was cleaned and checked for obstacles daily. Pasture composition was determined using 8 haphazard $1-\mathrm{m}^{2}$ samples cut before the beginning of the experiment and the material was sorted into the species that were previously planted, the portions were weighed, and relations were determined. The pasture was approximately 45:40:10:5 festulolium [tall fescue (Festuca arundinacea) $\times$ ryegrass (Lolium perenne L.) cross]: orchard grass (Dactylis glomerata L.): ryegrass (Lolium perenne L.): white clover (Trifolium repens). The pasture was divided into 16 paddocks of 1,400 $\mathrm{m}^{2}$ each managed using a rotational grazing system, where each group was introduced to a new paddock. A water trough located adjacent to the fence in each paddock was filled with fresh water automatically. No shade was provided on pasture.

Weather conditions (air temperature, relative humidity, rainfall, and wind speed) were recorded automatically throughout the study by an Environment Canada weather station in Agassiz, British Columbia, located adjacent to the research farm. During the course of the experiment (April to July 2013), the average \pm SD daily temperature recorded was $15.7^{\circ} \mathrm{C} \pm 3.6^{\circ} \mathrm{C}$, minimum temperature was $10.7^{\circ} \mathrm{C} \pm 3.3^{\circ} \mathrm{C}$, and maximum daily temperature was $20.6^{\circ} \mathrm{C} \pm 5.0^{\circ} \mathrm{C}$. Precipitation averaged $3.8 \pm 8.5 \mathrm{~mm}$ (range from 0 to $45.2 \mathrm{~mm} / \mathrm{d}$ ), relativity humidity was $73.2 \pm 9.3 \%$ (range from 34 to $99 \%$ ), and wind speed was $9.6 \pm 9.4 \mathrm{~m} / \mathrm{s}$ (range from 0 to $24 \mathrm{~m} / \mathrm{s}$ ).

Pasture samples were taken $1 \mathrm{~h}$ before the introduction of each new group. Each sample consisted of 6 sub-samples collected from the diagonal transects, a $0.25-\mathrm{m}^{2}$ patch was identified and clipped at $8 \mathrm{~cm}$ height. These sub-samples were pooled to create 1 representative sample per group. To calculate pasture mass, the 
sample weight was multiplied by the total area of the plot. Samples were dried at $55^{\circ} \mathrm{C}$ for $48 \mathrm{~h}$ to determine DM content. Dried samples were pooled, ground, and sent for nutritional analysis (A\&L Laboratories Inc., London, ON, Canada). During the experiment, pasture mass was (average $\pm \mathrm{SD}$ ) $1,900.09 \pm 203.1 \mathrm{~g} / \mathrm{m}^{2}$ of fresh matter, $22.1 \pm 2.3 \% \mathrm{DM}$, and (expressed as \% DM) $22.1 \pm 2.6 \% \mathrm{CP}, 57.1 \pm 2.6 \% \mathrm{NDF}$, and $34.3 \pm$ $2.3 \% \mathrm{ADF}$.

A TMR was formulated following the NRC (2001) guidelines to meet or exceed the requirements of a 550$\mathrm{kg}$ Holstein not producing milk, consisting of $31.2 \%$ ryegrass straw, $25.7 \%$ corn silage, $23.1 \%$ alfalfa hay, $12.5 \%$ concentrated mix, and $7.5 \%$ grass silage, with an overall \% DM of 48.7. The TMR was offered ad libitum in the experimental pen and delivered daily at approximately $0800 \mathrm{~h}$; feed was pushed up to the feed bunk 3 times per day at 1030, 1600, and $2230 \mathrm{~h}$. Water was available ad libitum from a self-filling water trough located in the feed alley of each pen.

Fresh TMR samples were taken on the second and last day of each replication immediately after the feed delivery. Samples were pooled to create 1 representative sample. Samples were dried at $60^{\circ} \mathrm{C}$ for $48 \mathrm{~h}$ to determine DM content and then ground and sent for nutritional analysis at A\&L Laboratories Inc. The TMR contained on average $46.4 \pm 2.4 \% \mathrm{DM}$ and (expressed as \% DM) $13.3 \pm 1.7 \% \mathrm{CP}, 49.1 \pm 2.1 \% \mathrm{NDF}$, and 31.6 $\pm 1.9 \%$ ADF.

\section{Measurements}

The animals were weighed and blood was sampled. This procedure was carried out weekly during the $3 \mathrm{wk}$ before introduction to pasture and again $12 \mathrm{~h}$ before and $72 \mathrm{~h}$ after introduction to pasture. Blood was analyzed for glucose following Wittrock et al. (2013), using a handheld electronic glucometer (Precision Xtra blood glucose kit; Abbott Diabetes Care, Alameda, CA) and BHB (Precision Xtra blood ketone kit; Abbott Diabetes Care) concentrations following the procedures described by Iwersen et al. (2009) for blood ketone analysis. Animals were gait scored (as described by Flower and Weary, 2006) on a scale of 1 to 5 ; subjects with a gait score $\geq 3$ were not included in the experiment.

\section{Behavior}

Behaviors were observed via continuous recording (Martin and Bateson, 2007) during the first hour immediately after animals were introduced to pasture, recording the number of stomps, agonistic interactions, vocalizations, and defecations (Table 1). During the next $3 \mathrm{~h}$ (i.e., $4 \mathrm{~h}$ in total), continuous recording was used to record latency to first graze and nibble the grass, and time spent nibbling, grazing, ruminating, walking, and alert. Within each sub-group, 3 heifers were identified as the focal animals and each animal was observed by a separate observer. Three observers collectively developed the data sheets and the descriptions of the behaviors and tested the definitions during a pilot trial. In a minute base inter-reliability test, the paired Kappa coefficient averaged 0.74.

\section{Statistical Analyses}

Number of stomps, agonistic interactions, vocalizations and defecations, latency to graze and nibble, glucose, and BHB blood concentration were considered as dependent variables and were compared between treatments. The group was considered the experimental unit; data from each individual $(\mathrm{n}=3)$ within a group were averaged. Prior to all analyses, data were checked for normality using the UNIVARIATE procedure in SAS (version 9.3, SAS Institute Inc., Cary, NC) and probability distribution plots. Because data were not normally distributed, treatments were compared using the nonparametric Mann-Whitney test. Results throughout the text are presented as median and first and third quartiles (Q1 and Q3) of the median; significance was declared at $P<0.05$.

\section{RESULTS}

Less than 30 min after heifers from both treatments were introduced to pasture they began to nibble the

Table 1. Behavior of naïve heifers recorded after introduction to pasture

\begin{tabular}{|c|c|}
\hline Behavior & Description \\
\hline Nibbling & Animal comes into contact with the grass, sniffs or performs small, quick bites. \\
\hline Grazing & $\begin{array}{l}\text { Animal grabbing and ingesting forage, may be stationary or moving forward for a period of at least } 5 \\
\text { consecutive minutes in which the animal consumed grass. }\end{array}$ \\
\hline Ruminating & Chewing with lateral jaw movements with the head at the same level or above its body, lying or standing. \\
\hline Walking & Animal moving, with the head above the grass. \\
\hline Alert & Animal stationary, lying, or walking with head up and ears positioned forward. \\
\hline Stomp & Animal lifts and kicks one or both hind legs. \\
\hline Agonistic interaction & Displacements or threats associated with a conflict between 2 individuals. \\
\hline
\end{tabular}


grass [Figure 1a; $\mathrm{W}(10)=21.0, \mathrm{Z}=-1.25, P=0.24]$. Soon after, heifers grouped with pasture-experienced cows began to graze, but the heifers within the naïve group took an additional hour before they began grazing [Figure $1 \mathrm{~b} ; \mathrm{W}(10)=15.0, \mathrm{Z}=-2.50, P=0.01]$.

During the first hour after heifers were introduced to pasture, animals in the experienced treatment showed fewer stomping events $[\mathrm{W}(11)=58.5, \mathrm{Z}=2.28, P=$ $0.02]$ and vocalizations $[\mathrm{W}(11)=57.0, \mathrm{Z}=2.07, P=$ $0.03]$. Number of agonistic interactions did not differ between treatments [Figure $2 ; \mathrm{W}(11)=45.0, \mathrm{Z}=0.36$, $P=0.72]$. Heifers in both treatments rarely defecated during the first hour on pasture [experienced: 0.33
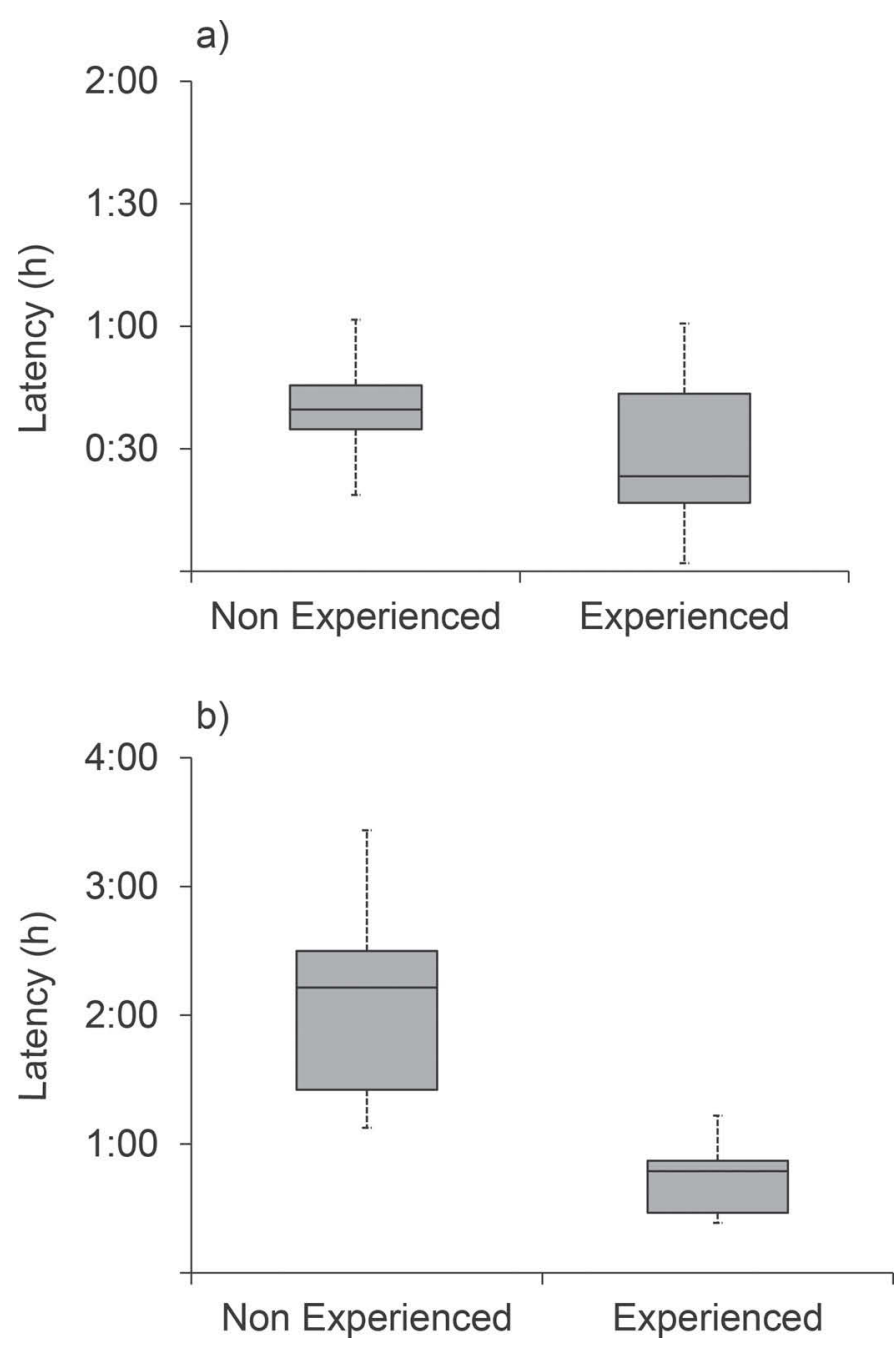

Figure 1. Latency (h) to (a) nibble and (b) graze for naïve heifers with and without the presence of grazing experienced cows $(n=7$ per treatment). The lower and upper ends of the boxes indicate the first and third quartiles, respectively. The quartiles \pm 1.5 the inter-quartile range are indicated by the whiskers. The line across the middle of the box identifies the median.
(0-1), median (Q1-Q3); nonexperienced 0 (0-0.33); $P$ $=0.21$.

Despite differences in latency to start to graze, total time spent grazing did not differ during the first $4 \mathrm{~h}$ on pasture [experienced: 40:58 (29:34-44:28) min:s vs. nonexperienced 27:01 (20:26-38:29) min:s; W(12) = $64.0, \mathrm{Z}=1.40, P=0.16]$. Time spent nibbling tended to be higher for nonexperienced than experienced animals during the first $4 \mathrm{~h}$ on pasture (experienced: 07:37 (03:10-13:07) min:s vs. nonexperienced: 19:06 (11:1349:07) min:s; $\mathrm{W}(12)=37.0, \mathrm{Z}=-1.92, P=0.06)$. All other behaviors observed (ruminating, walking, and alert) were similar in the 2 treatments (Table 2). Body weight and blood parameters (glucose and BHB) also did not vary with treatment $(P<0.10$; Table 3$)$.

\section{DISCUSSION}

Heifers kept in a group with experienced cows began grazing more rapidly than did naïve heifers kept with only naïve conspecifics. These results are consistent with the findings of Hessle (2009) who found that the presence of experienced animals increased grazing activity when providing calves first contact with seminatural grassland.

Previous work has found that naïve calves are more efficient at finding preferred food locations when provided with experienced steers as social models (Ksiksi and Laca, 2000). Another study found that grazing activity increased on the first day when 10-mo-old dairy steers were turned out on semi-natural grasslands with experienced cattle. However, this study did not show increased grazing times, grazing efficiency, or live weight gains after a month on pasture compared with control calves (Hessle, 2009). Heifers that were raised on pasture with just one species of grass but grouped with animals that were habituated to tropical pastures that included the presence of shrubs and trees, showed a higher use of shrubs and trees, and consumed a higher diversity of plants in comparison with animals introduced without a social model (Velázquez-Martínez et al., 2010). In contrast, another study failed to find any improvements in foraging ability of yearling heifers grouped with experienced conspecifics (Bailey et al., 2000).

Interestingly, we observed no treatment difference in the latency to start nibbling grass; all animals had experience eating feed from the ground in the free stall pens, so accessing feed from the ground in the new pasture environment would not be novel, but the ability to collect and ingest grass was a novel behavior for the animals. We speculate that the more rapid learning of heifers with experienced animals is associated with 
social learning. Social learning is defined as learning that is influenced by observation of or interaction with another individual, and has been described as an influential factor affecting the feeding behavior of many farmed species (Keeling and Hurnik, 1996; Launchbaugh and Howery, 2005). The major benefit of social learning is that the naïve animals experience increased efficiency and reduced risks associated with testing and exploring novel environments (reviewed by Bandura, 1977).

Naïve animals provided with social models are generally more efficient in ingesting forage in a new environment, suffer less from predation, and ingest fewer toxic plants compared with those not provided with a social model (Provenza and Cincotta, 1993; Launchbaugh and Howery, 2005). In the current study, we did not record the behavior of the experienced animals. We encourage future work to investigate the influence of the behaviors performed by the social model on the naive animals. Providing access to the dam has been shown to be important in the development of neonatal grazing behavior, but other dominant individuals in the group may also be influential (Thorhallsdottir et al., 1990; Howery et al., 1998). In the current study, age and experience were confounded; future work should investigate if the age of the experienced social models affects the first experiences observed of the naïve heifers when provided access to pasture for the first time.

The benefits of providing a social model appear to be concentrated in the first hours following introduction to pasture. Despite the differences in latency to first graze, all heifers began grazing within $4 \mathrm{~h}$ on pasture. Over the study, heifers housed together with experienced cows had no differences in weight gains, BHB, or blood glucose compared with heifers not provided a social model. These results are consistent with earlier work. For example, Hessle (2009) found that the company of experienced animals did not increase live weight gain of 10-mo-old calves after a month on pasture. Similarly, when heifers were transferred from a grass monoculture pasture to a diverse plant species environment, with or without the presence of experienced animals, weight gain was positive for both treatments (VelázquezMartínez et al., 2010). More recent work by Lopes et al. (2013) found that previous grazing experience as a heifer affected behavior and milk production of cows during the first days on pasture but not when averaged over a 2-mo period.

One previous study found that mixing younger cattle with older animals on pasture increases the number of aggressive social interactions, which in turn may reduce time spent grazing (Phillips and Rind, 2001). In the current study, we found that heifers put out on pasture for the first time with or without the presence of older experienced animals engaged in the same number of agonistic interactions. These results may be explained by the use of groups that had been stable with no
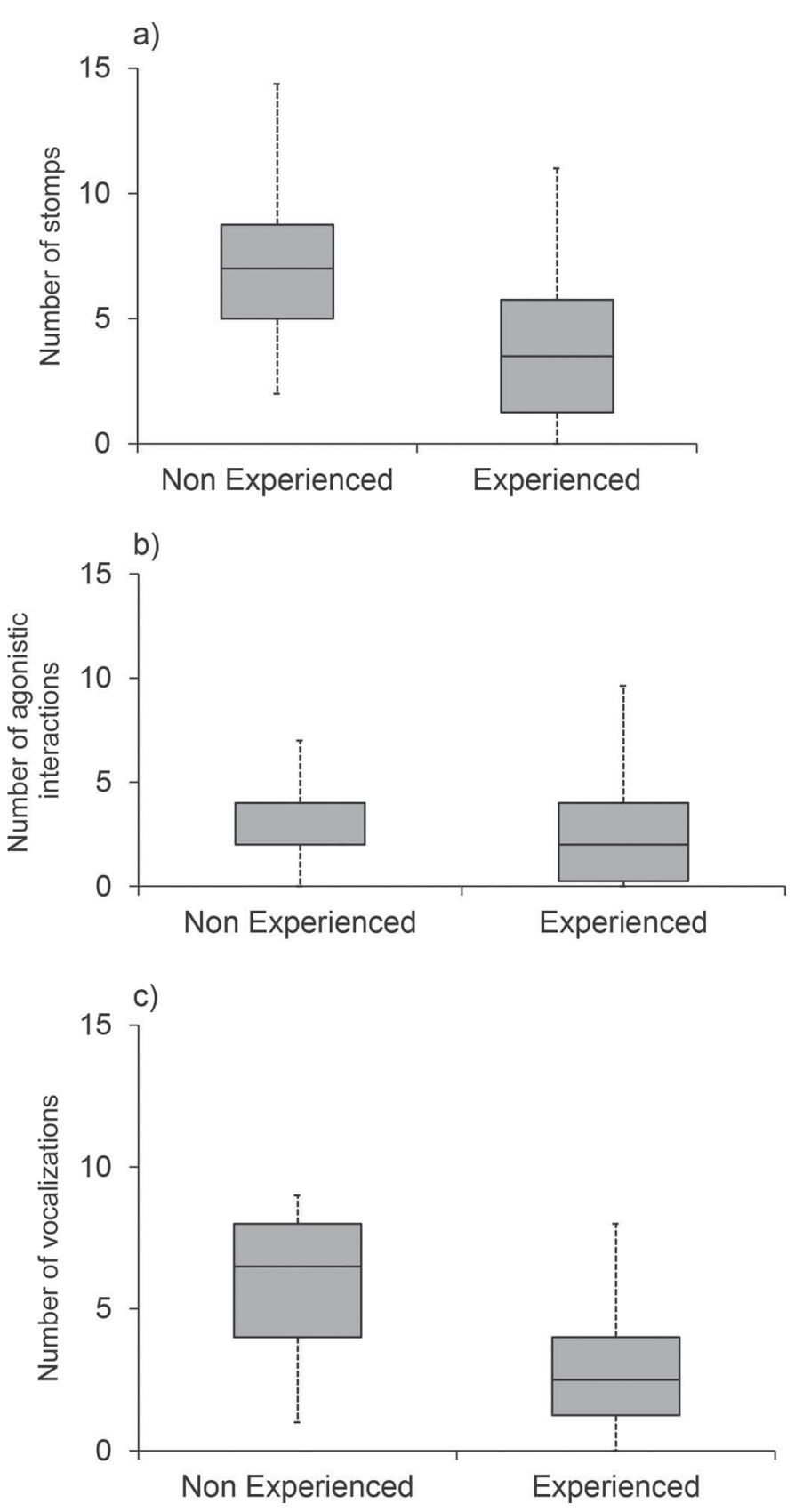

Figure 2. The number of (a) stomps, (b) agonistic interactions, and (c) vocalization for naïve heifers with or without the presence of grazing experienced cows observed during the first hour immediately after introduction to pasture ( $\mathrm{n}=7$ per treatment). The lower and upper ends of the boxes indicate the first and third quartiles, respectively. The quartiles \pm 1.5 the inter-quartile range are indicated by the whiskers. The line across the middle of the box identifies the median. 
Table 2. Median (quartile 1 - quartile 3) time spent ruminating, walking, and alert (min:s) for naïve heifers with or without the presence of grazing experienced cows ( $\mathrm{n}=7$ per treatment) observed during the first $4 \mathrm{~h}$ after animals were introduced to pasture

\begin{tabular}{lccc}
\hline $\begin{array}{l}\text { Time } \\
\text { (min:s) }\end{array}$ & Nonexperienced & Experienced & $P$-value \\
\hline Rumination & $00: 15(0: 07-0: 27)$ & $00: 08(00: 03-00: 19)$ & 0.25 \\
Walking & $47: 20(29: 19-59: 24)$ & $39: 47(21: 04-57: 14)$ & 0.84 \\
Alert & $37: 25(28: 20-55: 30)$ & $46: 27(11: 10-58: 24)$ & 0.60 \\
\hline
\end{tabular}

Table 3. Median (quartile 1 - quartile 3) of the difference before and $3 \mathrm{~d}$ after the animals were introduced to pasture for BW, glucose (Wittrock et al., 2013), and BHB (Iwersen et al., 2009) of naïve heifers with or without the presence of grazing experienced cows $(n=7$ per treatment)

\begin{tabular}{lccc}
\hline Variable & Nonexperienced & Experienced & $P$-value $^{1}$ \\
\hline BW $(\mathrm{kg})$ & $-16.66(-23.33--6.67)$ & $-25(-33--6.67)$ & 0.77 \\
Glucose $(\mathrm{mmol} / \mathrm{L})$ & $6.16(-0.33-13.00)$ & $6.16(-0.67-13.00)$ & 0.14 \\
BHB $(\mathrm{mmol} / \mathrm{L})$ & $-0.07(-0.07--0.33)$ & $0(-0.10-0.16)$ & 0.75 \\
\hline
\end{tabular}

${ }^{1} P$-values are for the test of treatment.

new animals introduced for over 4 wk before testing. Regrouping is known to cause increased competitive behavior in cattle, and heifers are frequently subjected to aggressive behaviors following grouping with older cows (Neisen et al., 2009).

\section{CONCLUSIONS}

Providing heifers with pasture-experienced social companions when first introduced to pasture promotes a more rapid onset of grazing. The presence of habituated older experienced companions may improve the ability of heifers to adapt to pasture.

\section{ACKNOWLEDGMENTS}

We thank the staff and students at the UBC Dairy Education and Research Centre who helped in this experiment, especially Eraldo Drago Filho and Rolnei Ruã Dáros for their help with data collection. J. H. C. Costa was supported by a scholarship from CNPq, Brazil. W. G. Costa was supported by an Emerging Leaders in the Americas Program (ELAP) scholarship. M. A. G. von Keyserlingk and D. M. Weary are supported by Canada's Natural Sciences and Engineering Research Council (NSERC) Industrial Research Chair Program with industry contributions from the Dairy Farmers of Canada (Ottawa, ON, Canada), British Columbia Dairy Association (Burnaby, BC Canada), Westgen Endowment Fund (Milner, BC, Canada), Intervet Canada Corporation (Kirkland, QC, Canada), Zoetis (Kirkland, QC, Canada), Novus International Inc. (Oakville, ON, Canada), BC Cattle Industry Development Fund (Kamloops, BC, Canada), Alberta
Milk (Edmonton, AB, Canada), Valacta (St. Anne-deBellevue, QC, Canada), and CanWest DHI (Guelph, ON, Canada).

\section{REFERENCES}

Bailey, D. W., I. D. Howery, and D. L. Boss. 2000. Effects of social facilitation for locating feeding sites by cattle in an eight-arm radial maze. Appl. Anim. Behav. Sci. 68:93-105.

Bandura, A. 1977. Social Learning Theory. Prentice-Hall, Englewood Cliffs, NJ.

Costa, J. H. C., R. R. Daros, M. A. G. von Keyserlingk, and D. M. Weary. 2014. Complex social housing reduces food neophobia in dairy calves. J. Dairy Sci. 97:7804-7810.

De Paula Vieira, A., M. A. G. von Keyserlingk, and D. M. Weary. 2010. Effects of pair versus single housing on performance and behavior of dairy calves before and after weaning from milk. J. Dairy Sci. 93:3079-3085.

De Paula Vieira, A., M. A. G. von Keyserlingk, and D. M. Weary. 2012. Presence of an older weaned companion influences feeding behavior and improves performance of dairy calves before and after weaning from milk. J. Dairy Sci. 95:3218-3224.

Edmonson, A. J., I. J. Lean, L. D. Weaver, T. Farver, and G. Webster. 1989. A body condition scoring chart for Holstein dairy cows. J. Dairy Sci. 72:68-78.

Enríquez, D., M. J. Hötzel, and R. Ungerfeld. 2011. Minimising the stress of weaning of beef calves: A review. Acta Vet. Scand. 53:28.

Flower, F. C., and D. M. Weary. 2006. Effect of hoof pathologies on subjective assessments of dairy cow gait. J. Dairy Sci. 89:139-146.

Fulwider, W. K., T. Grandin, B. E. Rollin, T. E. Engle, N. L. Dalsted, and W. D. Lamm. 2008. Survey of dairy management practices on one hundred thirteen north central and northeastern United States dairies. J. Dairy Sci. 91:1686-1692.

Hanson, J. C., D. M. Johnson, E. Lichtenberg, and K. Minegishi. 2013. Competitiveness of management-intensive grazing dairies in the mid-Atlantic region from 1995 to 2009. J. Dairy Sci. 96:1894-1904.

Hasegawa, N., A. Nishiwaki, K. Sugawara, and I. Ito. 1997. The effects of social exchange between two groups of lactating primiparous heifers on milk production, dominance order, behavior and adrenocortical response. Appl. Anim. Behav. Sci. 51:15-27.

Hessle, A. K. 2009. Effects of social learning on foraging behaviour and live weight gain in first to season grazing calves. Appl. Anim. Behav. Sci. 116:150-155. 
Howery, L. D., F. D. Provenza, R. E. Banner, and C. B. Scott. 1998. Social and environmental factors influence cattle distribution on rangeland. Appl. Anim. Behav. Sci. 55:231-244.

Iwersen, M., U. Falkenberg, R. Voigtsberger, D. Forderung, and W. Heuwieser. 2009. Evaluation of an electronic cowside test to detect subclinical ketosis in dairy cows. J. Dairy Sci. 92:2618-2624.

Keeling, L. J., and J. F. Hurnik. 1996. Social facilitation acts more on the appetitive than the consummatory phase of feeding behaviour in domestic fowl. Anim. Behav. 52:11-15.

Ksiksi, T., and E. A. Laca. 2000. Can social interactions affect food searching efficiency of cattle? Rangeland J. 22:235-242.

Launchbaugh, K. L., and L. D. Howery. 2005. Understanding landscape use patterns of livestock as a consequence of foraging behavior. Rangeland Ecol. Manag. 58:99-108.

Lopes, F., W. Coblentz, P. C. Hoffman, and D. K. Combs. 2013. Assessment of heifer grazing experience on short-term adaptation to pasture and performance as lactating cows. J. Dairy Sci. 96:31383152.

Martin, P., and P. Bateson. 2007. Measuring Behaviour. An Introductory Guide. 3rd ed. Cambridge University Press, Cambridge, UK.

NAHMS. 2010. Dairy 2007. Facility Characteristics and Cow Comfort on U.S. Dairy Operations, 2007. Vol. \#524.1210. USDA:APHIS:VS:CEAH, Fort Collins, CO.

Neisen, G., B. Wechsler, and L. Gygax. 2009. Effects of the introduction of single heifers or pairs of heifers into dairy-cow herds on the temporal and spatial associations of heifers and cows. Appl. Anim. Behav. Sci. 119:127-136.

NRC. 2001. National Research Council Nutrient Requirements of Dairy Cattle. 7th rev. ed. Natl. Acad. Sci., Washington, DC.
Phillips, C. J. C., and M. I. Rind. 2001. The effects on production and behavior of mixing uniparous and multiparous cows. J. Dairy Sci 84:2424-2429.

Provenza, F. D., and R. P. Cincotta. 1993. Foraging as a self-organizational learning process: Accepting adaptability at the expense of predictability. Pages 78-101 in Diet Selection: An Interdisciplinary Approach to Foraging Behavior. Wiley and Sons, New York, NY.

Thorhallsdottir, A. G., F. D. Provenza, and D. F. Balph. 1990. The role of the mother in the intake of harmful foods by lambs. Appl. Anim. Behav. Sci. 25:35-44.

USDA. 2008. Dairy 2007, Part III: Reference of Dairy Cattle Health and Management Practices in the United States. 2007. USDA, National Animal Health Monitoring System, Fort Collins, CO.

Vasseur, E., F. Borderas, R. I. Cue, D. Lefebvre, D. Pellerin, J. Rushen, K. M. Wade, and A. M. dePassillé. 2010. A survey of dairy calf management practices in Canada that affect animal welfare. J. Dairy Sci. 93:1307-1315

Velázquez-Martínez, M. S. López-Ortiz, O. Hernández-Mendo, P. Díaz-Rivera, S. Pérez-Elizalde, and J. Gallegos-Sánchez. 2010. Foraging behavior of heifers with or without social models in an unfamiliar site containing high plant diversity. Livest. Sci. 31:73-82.

von Keyserlingk, M. A. G., and D. M. Weary. 2010. Review: Feeding behaviour of dairy cattle: Measures and applications. Can. J. Anim. Sci. 90:303-309.

Wittrock, J. A. M., T. F. Duffield, and S. J. LeBlanc. 2013. Short communication: Validation of a point-of-care glucometer for use in dairy cows. J. Dairy Sci. 96:4514-4518. 